
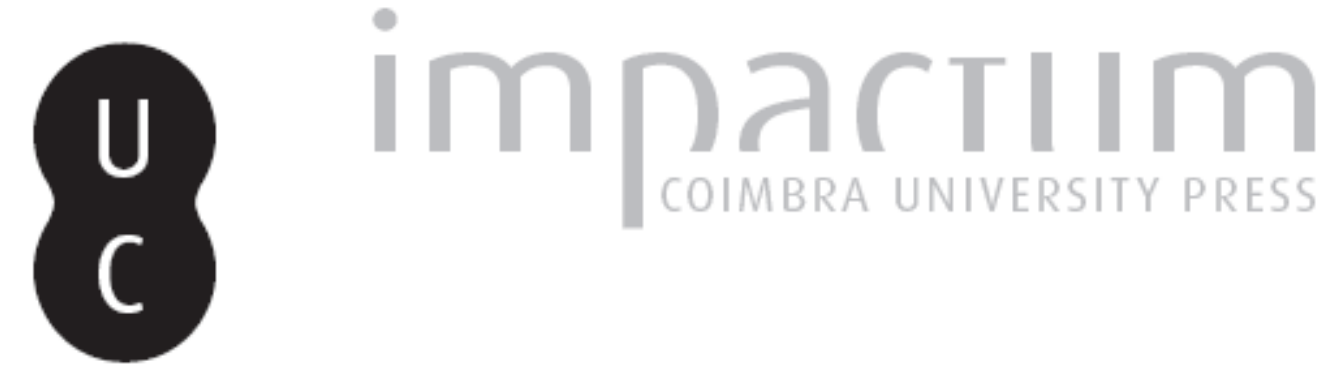

\title{
Avaliação de competências de literacia mediática: instrumentos de recolha de informação e opções teóricometodológicas
}

\author{
Autor(es): $\quad$ Lopes, Paula
}

Publicado por: Imprensa da Universidade de Coimbra

URL persistente:

URI:http://hdl.handle.net/10316.2/38139

DOI:

DOI:http://dx.doi.org/10.14195/2183-5462_27_2

Accessed : $\quad$ 26-Apr-2023 14:11:23

A navegação consulta e descarregamento dos títulos inseridos nas Bibliotecas Digitais UC Digitalis, UC Pombalina e UC Impactum, pressupõem a aceitação plena e sem reservas dos Termos e Condições de Uso destas Bibliotecas Digitais, disponíveis em https://digitalis.uc.pt/pt-pt/termos.

Conforme exposto nos referidos Termos e Condições de Uso, o descarregamento de títulos de acesso restrito requer uma licença válida de autorização devendo o utilizador aceder ao(s) documento(s) a partir de um endereço de IP da instituição detentora da supramencionada licença.

Ao utilizador é apenas permitido o descarregamento para uso pessoal, pelo que o emprego do(s) título(s) descarregado(s) para outro fim, designadamente comercial, carece de autorização do respetivo autor ou editor da obra.

Na medida em que todas as obras da UC Digitalis se encontram protegidas pelo Código do Direito de Autor e Direitos Conexos e demais legislação aplicável, toda a cópia, parcial ou total, deste documento, nos casos em que é legalmente admitida, deverá conter ou fazer-se acompanhar por este aviso.

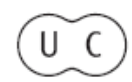




\section{Mediag Ornalismo}

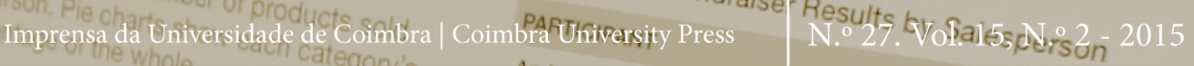

\section{U.m

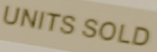 \\ EDUCÂÇÃO PARA OS}

MEDIA NA ERA DIGITAL
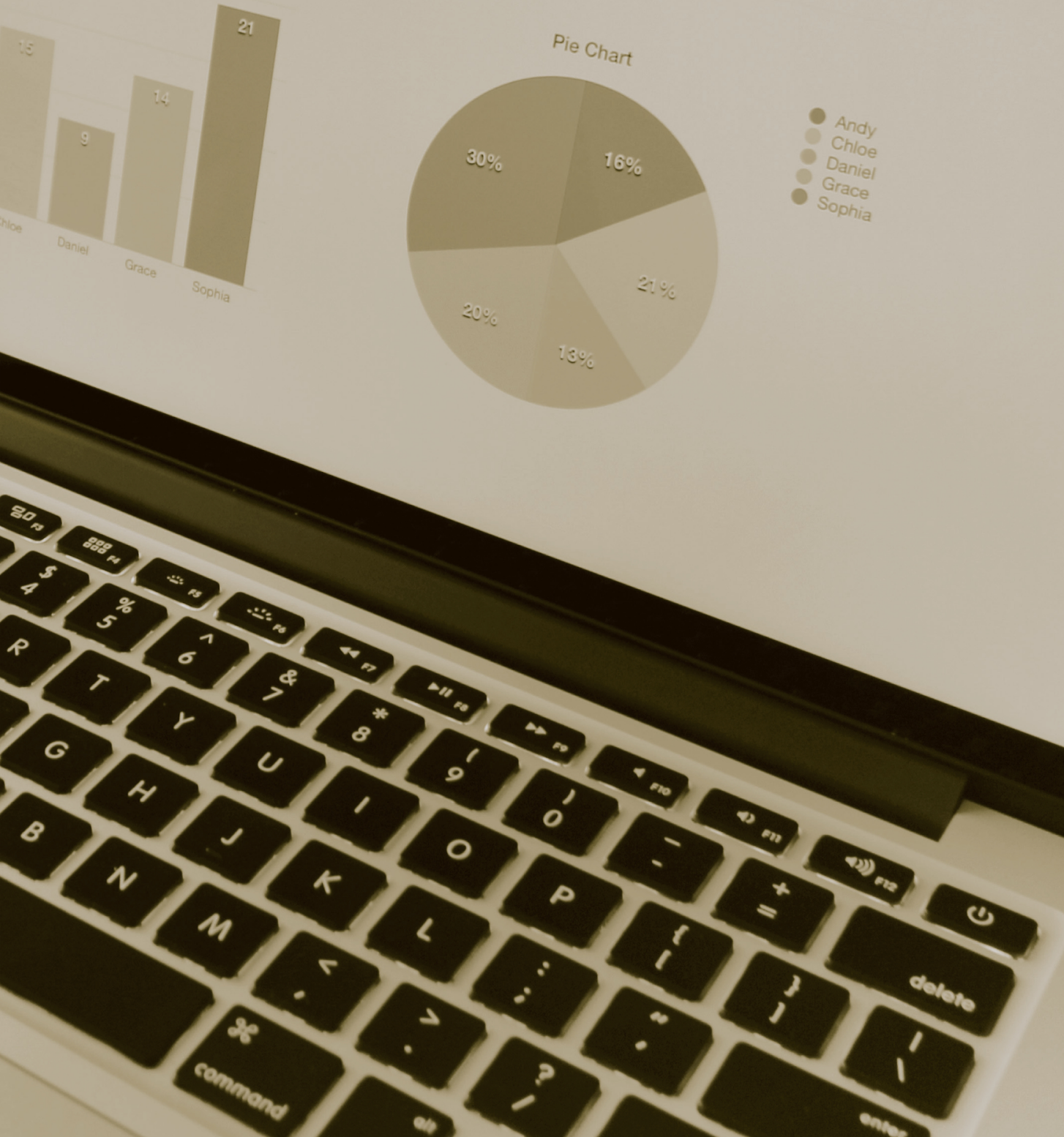


\title{
AVALIAÇÃO DE COMPETÊNCIAS DE LITERACIA MEDIÁTICA: INSTRUMENTOS DE RECOLHA DE INFORMAÇÃO E OPÇÕES TEÓRICO-METODOLÓGICAS \\ MEDIA LITERACY ASSESSMENT: METHODOLOGICAL INSTRUMENTS AND THEORETICAL-METHODOLOGICAL OPTIONS
}

\author{
PAULA LOPES \\ PAULALOPES@NETCABO.PT \\ UNIVERSIDADE AUTÓNOMA DE LISBOA, CENTRO DE ESTUDOS DE COMUNICAÇÃO \\ E SOCIEDADE, DA UNIVERSIDADE DO MINHO (CECS-UM)
}

Resumo

A avaliação da literacia mediática dos cidadãos e o seu enquadramento em níveis tem estado na ordem do dia. Desde 2007 que a União Europeia (UE) recomenda que, de três em três anos, a Comissão Europeia deva apresentar um relatório sobre os níveis de literacia mediática de todos os estados-membros (UE, 2007). Para responder a esta solicitação, os projetos têm surgido um pouco por toda a Europa, na academia e fora dela. Se parece evidente que o interesse por este domínio de investigação tem crescido nos últimos anos, também é uma evidência que a pesquisa empírica ainda é confusa e insuficiente. Neste texto, desvendamos o processo de operacionalização de um instrumento metodológico concebido e aplicado na investigação “Literacia mediática e cidadania. Práticas e competências de adultos em formação na Grande Lisboa", desenvolvida, entre 2009 e 2013, no CIES-IUL: uma prova de literacia mediática para avaliação de competências de literacia mediática.

\footnotetext{
Palavras-chave

Literacia mediática, competências de literacia mediática, prova de literacia mediática.
}

\section{Abstract}

The evaluation of the media literacy of citizens and the framing in proficiency levels has been on the agenda. Since 2007 that the EU recommends that, every three years, the Commission should present a report on the levels of media literacy of all member states (European Union, 2007). To respond to this request, different projects have emerged all over Europe, in the academy and beyond.

Although interest in this field of research has grown in recent years, it is also evident that empirical research is still poorly grounded and scarce.

In this paper, we describe the operationalization of a methodological instrument designed and applied in the research project "Media literacy and citizenship. Practices and competencies of adults in training in Grande Lisboa", developed, between 2009 and 2013, in CIES-IUL: a test of media literacy, to assess media literacy skills/competencies.

KEYWORDS

Media literacy, media literacy skills and competencies, media literacy test. 


\title{
AVALIAÇÃO DE COMPETÊNCIAS DE LITERACIA MEDIÁTICA: INSTRUMENTOS DE RECOLHA DE INFORMAÇÃO E OPÇÕES TEÓRICO-METODOLÓGICAS
}

\author{
PAULA LOPES \\ PAULALOPES@NETCABO.PT \\ UNIVERSIDADE AUTÓNOMA DE LISBOA, CENTRO DE ESTUDOS DE COMUNICAÇÃO \\ E SOCIEDADE, DA UNIVERSIDADE DO MINHO (CECS-UM)
}

\section{Introdução}

De forma mais ou menos simplista, podemos dizer que uma prática corresponde a um 'fazer' e uma competência a um 'saber-fazer'. 0 conceito de competência - central quando se fala em literacia - traduz a capacidade de responder a exigências complexas num determinado contexto através da mobilização de pré-requisitos psicossociais (Rychen e Salganik, 2003).

Assim, se práticas mediáticas e competências de literacia mediática não são uma e a mesma coisa, não devem ser investigadas, avaliadas ou medidas através de um mesmo instrumento metodológico de recolha de informação. Para objetivos diferentes, instrumentos distintos.

A avaliação da literacia mediática dos indivíduos tem assentado sobretudo em referenciais teórico-empíricos quantitativos-extensivos e tem incidido mais sobre práticas do que competências (cf., por exemplo, o EU Kids Online, os estudos do Office of Communications - Ofcom - ou do Observatório da Comunicação - Obercom). 0 método de investigação mais comum neste domínio é o inquérito por questionário, em suporte papel ou online. A metodologia parece-nos adequada à inquirição das práticas mediáticas, mas não à avaliação das competências de literacia mediática dos indivíduos. Neste caso, o das competências, julgamos mais adequado recorrer a modelos como o do Programme for International Student Assessment (PISA), do International Adult Literacy Survey (IALS) ou do Programme for the International Assessment of Adult Competencies (PIAAC).

Neste texto, desvendamos o framework de uma Prova de Literacia Mediática, concebida no âmbito do projeto de investigação "Literacia mediática e cidadania. Práticas e competências de adultos em formação na Grande Lisboa" (Programa de Doutoramento em Sociologia, ISCTE-IUL), bem como a operacionalização do seu quadro teórico-metodológico. A sua construção traduz empiricamente o esforço teórico reflexivo que lhe está subjacente: o mapa conceptual, as dimensões, os domínios operacionais de processamento, as tarefas e os critérios que sustentam a medição. 


\section{Avaliação de competências: Framework conceptual da Prova de Literacia Mediática}

Como avaliar a literacia mediática dos cidadãos? 0 que medir, como medir e com que instrumentos? A resposta a estas perguntas mostra-se ainda extremamente complexa'.

0 conceito de literacia - remetendo, por um lado, para conhecimentos e, por outro, para competências mobilizadas em contextos particulares - traduz uma natureza multidimensional, dinâmica, processual. Os domínios avaliados nos grandes surveys internacionais, como o IALS, o ALL (Adult Literacy and Lifeskills Survey) ou o PIAAC, espelham bem essa diversidade (e renovação) conceptual ${ }^{2}$. Recentemente, à avaliação direta de competências básicas de literacia (como a literacia em leitura ou a numeracia, por exemplo), o PIAAC (OECD, 2009) acrescenta a avaliação direta de competências de literacia digital (solicitando a resolução de problemas em cenários tecnologicamente enriquecidos). Por um lado, alarga-se substancialmente o leque de tarefas e operações; por outro, requer-se o processamento de informação proveniente de diferentes media, em diferentes formatos e servindo diferentes objetivos (Levy, 2010, p. 12). Em rigor, ampliam-se as dimensões cognitivas avaliadas.

Tal como a literacia digital, a literacia mediática é um complemento à literacia dita "tradicional". A literacia mediática, entendida como uma competência do sujeito - como "a sua cultura dos media" (Sorlin, 1997, p. 78) -, consolida-se enquanto recurso básico indispensável no acesso ao conhecimento e à informação numa sociedade multimediática cada vez mais mutante e global. É essa competência, mobilizada quotidianamente em variadíssimas situações, que permite a cada indivíduo aceder, compreender e avaliar criticamente, mas também criar e comunicar mensagens mediáticas.

Centrar a investigação nas competências de literacia mediática de tipo operatório (Costa, 2003, p.188) - na resolução de tarefas ou problemas, nos processos de atribuição de sentido - invoca a tradição empírica dos grandes estudos extensivos de literacia (como, por exemplo, o Estudo Nacional de Literacia - ENL, o IALS, o ALL ou o PIAAC) e a investigação mais ou menos recente no domínio da literacia mediática (Quin e McMahon, 1991, 1995; Hobbs e Frost, 2003; Arke, 2005; Mihailidis, 2008; João e Menezes, 2008; Arke e Primack, 2009; EAVI, 2009, 2011), articulando e integrando contributos de abordagens teóricas tão diversas como 0 interaccionismo simbólico (Mead, 1926; Goffman, 1974), a psicologia cognitiva (Rumelhart,

1 Testing e Refining Criteria to Access Media Literacy Levels in Europe. Final Report(2011), o mais recente documento da EAVI - European Association for Viewers Interests para a Comissão Europeia representa um bom exemplo desta complexidade. A aplicação, sugerida aos estados-membros, de um inquérito por questionário para avaliação/medição de competências críticas e de competências comunicativas não nos parece a metodologia mais adequada aos objetivos, uma limitação que, aliás, é reconhecida no próprio relatório.

2 Domínios avaliados nos principais estudos internacionais de literacia: "literacia em prosa", "literacia documental", "literacia quantitativa" (IALS, 1994-2000); "literacia em prosa”, "literacia documental", "numeracia", "resolução de problemas" (ALL, 2002-2006); "componentes de leitura", "literacia em leitura", "numeracia", "resolução de problemas em cenários tecnologicamente enriquecidos" (PIAAC, 2008-2013). Fonte: PIAAC (OECD, 2009) 
1977; Gagné et al., 1993; Morais, 1997, 2002, 2010; Whitehurst e Lonigan, 2001) ou as teorias da receção (Katz, Gurevitch e Hass, 1973; Hall et al, 1978/1999; Hall, 1980; Fiske, 1987; Jensen, 1991), e muito em particular da compreensão do texto jornalístico (Tuchman, 1978; van Dijk, 1983a, 1983b, 1988, 1990, 2002, 2008, 2009; Fowler, 1991; Fairclough, 1995; Deacon et al., 1999; Mathieu, 2009; Coleman, Anthony e Morrison, 2009).

Numa abordagem extensiva, o instrumento mais adequado à avaliação direta de competências de literacia é, comprovadamente (cf. ENL, IALS, ALL, PIAAC, por exemplo), o que podemos designar por "prova de literacia", um teste composto por um conjunto de tarefas e operações que simulam situações do quotidiano. A prova materializa-se num caderno em suporte pape ${ }^{3}$, solicitando uma resposta individual em ambiente controlado, na presença de um entrevistador e sem limite de tempo para a resolução dos exercícios que a compõem. A Prova de Literacia Mediática (PLM) foi concebida nestes moldes, seguindo de perto modelos (bem) testados nos grandes estudos internacionais.

A PLM ajudará a perceber o papel (decisivo) da literacia mediática na vida dos cidadãos - muito concretamente a forma como estes (re)conhecem o universo mediático, a forma como interpretam e avaliam criticamente mensagens mediáticas e a forma como as criam e comunicam.

\section{Literacia mediática: 0 conceito}

0 conceito de literacia mediática constituiu o ponto de partida para a operacionalização da PLM.

Literacia mediática é a capacidade de aceder, analisar, avaliar, criar e comunicar mensagens em diversos contextos (Aufderheide e Firestone, 1993; Thoman, 2003; Livingstone, 2003; Thoman e Jolls, 2003). Na mesma linha teórica conceptual, um grupo de peritos europeus (Media literacy expert group $p^{4}$ validou, no último trimestre de 2006, uma definição europeia de literacia mediática, a qual é proposta como "a capacidade de aceder aos media, de compreender e avaliar de modo crítico os diferentes aspetos dos media e dos seus conteúdos, e de criar comunicações em diversos contextos" ${ }^{5}$. 0 conceito (polissémico) remete, portanto, para quatro domínios operacionais de processamento da informação:

3 No PIAAC, recorreu-se também ao enunciado em suporte eletrónico, disponibilizado em computador portátil, para a avaliação direta de competências de literacia digital.

4 A constituição do grupo de peritos pode ser consultada em http://ec.europa.eu/culture/media/ literacy/docs/expert_group.pdf

5 Cf. Comunicação da Comissão ao Parlamento Europeu, ao Conselho, ao Comité Económico e Social Europeu e ao Comité das Regiões: uma abordagem europeia da literacia mediática no ambiente digital, de 20 de dezembro de 2007. 
Figura n. ${ }^{0} 1$ - Literacia Mediática: Domínios operacionais de processamento da informação

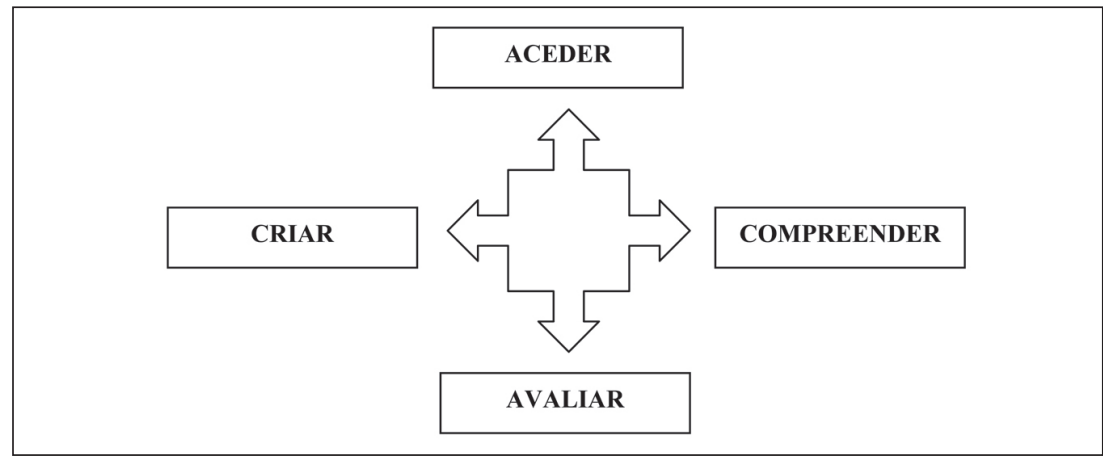

No primeiro domínio (aceder), sobressai a relação entre 0 indivíduo e o meio enquanto plataforma de procura/aquisição de informação. Aceder aos media constitui, simultaneamente, uma prática e uma competência: de forma deliberada e continuada ${ }^{6}$, acede aos media quem tem meios (tecnologia, por exemplo), know-how e competências para o fazer. Na sociedade da informação e do conhecimento, das redes e em rede, acede e usa eficazmente os media quem sabe como e sabe o que fazer com diversos equipamentos e dispositivos, com diversas tecnologias e aplicações em diversos contextos ${ }^{7}$. Teun A. van Dijk (apud Pereira, 2013) sugere a análise do acesso tendo em conta quatro dimensões: motivacional (ter predisposição/ motivação para aceder), material (ter acesso à tecnologia), competências de acesso (de literacia, cognitivas, tecnológicas, entre outras), usos do acesso (contextos, autonomia, qualidade do uso).

Como sabemos, 0 acesso aos media enquanto conjunto de práticas (autodeclaradas) é habitualmente medido através de um instrumento de recolha de informação que não uma prova de literacia mediática, bem mais adequado: 0 inquérito por questionário. A informação recolhida prende-se, por exemplo, com indicadores relacionados com hábitos, práticas e consumos de leitura (livros e imprensa). de audição de rádio, de visionamento de televisão e de utilização de internet, nas suas várias dimensões.

0 acesso aos media enquanto conjunto de competências, embora não submetido a medição pela resolução específica de uma prova de literacia mediática, tem vindo a ser, de alguma forma, sujeito a avaliação direta. Neste particular, saliente-se o novo domínio PIAAC "Resolução de problemas em cenários tecnologicamente enriquecidos" ["a capacidade de encontrar, avaliar e usar informação proveniente de diversas fontes para resolver problemas como procurar um livro numa biblioteca ou navegar numa página de internet complexa" (Ávila et al., 2011, p. 7)] que submete a avaliação 0 acesso à informação: a resolução de uma tarefa, de uma operação, implica, quase sempre, o acesso online à informação. Embora o domínio não tenha sido especificamente concebido visando a medição

6 E não unicamente pela imersão na cultura mediática, característica da contemporaneidade.

7 A sociedade dos computadores, dos PDA, dos ebooks, dos tablets, dos smartphones... 
direta do acesso enquanto uma competência de literacia mediática, visa sem dúvida competências de literacia digital (competências em tecnologias de informação e comunicação - TIC, estreitamente relacionadas com as competências de literacia mediática), pela utilização, pela primeira vez numa avaliação internacional de competências de literacia, de computadores portáteis para aceder a/procurar informação. Na mesma linha reflexiva, também o Eyetrack, do americano Poynter Institute (numa parceria com a Universidade de Stanford), estuda padrões de comportamento no processamento da informação. 0 estudo analisa e compara a leitura de jornais impressos e digitais (webjornais), desvendando padrões de leitura no acesso aos media, a partir da medição de movimentos oculares monitorizados, em tempo real, graças ao uso da tecnologia Eye Tracking: em 1990, 0 Poynter testou a forma como as pessoas leem notícias na imprensa; em 2000 e 2003, testou a leitura de notícias online; em 2007, avaliou e comparou a leitura de notícias em ambos os suportes (imprensa e online); e em 2012, observou como as pessoas interagem com a informação em suportes tablet (no caso, iPad).

0 segundo (compreender) e o terceiro domínios (avaliar) evidenciam o indivíduo e a sua circunstância: a sua própria cultura dos media (knowledge about Media + understanding Media). Constituem, por assim dizer, o núcleo duro/central das competências de literacia mediática a mobilizar numa prova de literacia mediática. A avaliação crítica - a "critical autonomy", a capacidade de pensar por si próprio, de que nos fala Len Masterman - tem sido frequentemente identificada como a mais importante das competências na relação indivíduo-media (Masterman, 1985; Feuerstein, 1999; Silverblatt, 2001; Fedorov, 2003; Jenkins, 2007, Pérez-Tornero e Varis, 2010). Estes domínios têm vindo a ser avaliados desde os anos 90 do século XX, por investigadores como Quin e McMahon (1991, 1995), Feuerstein (1999), Hobbs e Frost (2003), Arke (2005), Mihailidis (2008) ou Arke e Primack (2009).

0 quarto domínio (criar) expressa a produção individual de conteúdos mediáticos e a sua comunicação, em diversos contextos (Hobbs, 1998; Silverblatt, 2001; Potter, 2001, 2004; Thoman e Jolls, 2003; Livingstone, 2004a, 2004b, 2011; Kist, 2005; Jenkins, 2007; Pérez-Tornero e Varis, 2010).

De forma simplificada, digamos que os domínios a avaliar através da PLM dizem respeito a dois tipos de operações de processamento de informação - descodificação (ou compreensão enquanto "descodificação ativa"), isto é, retradução da mensagem para se extrair o seu significado; e codificação, isto é, tradução da mensagem para uma linguagem ou código adequado aos meios de transmissão e aos recetores visados (McQuail e Windahl, 2003, p. 13) - e remetem para a problemática do empowerment do indivíduo (muito em voga nas mais recentes teorias da receção), reconhecendo o seu poder e o seu papel na sociedade da informação e do conhecimento.

Os domínios objetivados e validados pelo Media literacy expert group, sujeitos a avaliação direta na PLM (compreender, avaliar, criar) ${ }^{8}$, foram operacionalizados

8 Como já sabemos, no âmbito desta investigação, o domínio "Aceder" foi avaliado através de um inquérito por questionário: a medição visou, portanto, práticas e consumos mediáticos (auto)declarados pelos sujeitos. 
com as seguintes designações: "conhecer e compreender"9 (dois eixos de análise: um centrado no conhecimento; outro mais reflexivo), "avaliar criticamente" e "criar para comunicar".

Figura n. ${ }^{\circ} 2$ - Domínios operacionais de processamento da informação presentes na PLM

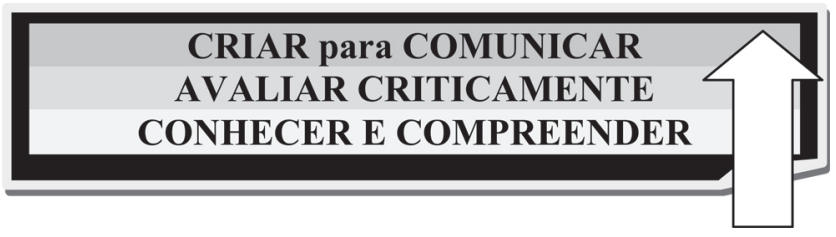

Em detalhe, a descrição de cada domínio:

Quadro n. ${ }^{0} 1$ - Descrição dos domínios operacionais de processamento da informaç̧ão

\begin{tabular}{|c|l|}
\hline Domínio operacional: & \multicolumn{1}{|c|}{ Descrição: } \\
\hline \multirow{2}{*}{$\begin{array}{c}\text { Conhecer (a) e Compreender (b) } \\
\text { (CONHECIMENTOS \& }\end{array}$} & $\begin{array}{l}\text { (a) Diz respeito ao (re)conhecimento do universo mediático e à identificação } \\
\text { de componentes básicos: símbolos, marcas, palavras, técnicas. } \\
\text { (b) Diz respeito à capacidade de interpretar e compreender a forma e a } \\
\text { estrutura de uma mensagem mediática, o seu conteúdo e o contexto em } \\
\text { que ocorre. Em pormenor, refere-se à interpretação de mensagens e de } \\
\text { conteúdos usando variados conceitos e ao uso de estratégias cognitivas } \\
\text { incluindo comparação/contraste, distinção factos/opinião e identificação } \\
\text { causa/efeito. }\end{array}$ \\
\hline $\begin{array}{c}\text { Avaliar criticamente } \\
\text { (COMPETÊNCIAS) }\end{array}$ & $\begin{array}{l}\text { Diz respeito à capacidade de avaliar mensagens, fazer julgamentos acerca } \\
\text { da sua veracidade, qualidade e relevância. Em pormenor, refere-se à } \\
\text { apreciação de mensagens de diferentes géneros e formatos, à avaliação da } \\
\text { qualidade de uma mensagem com base na seu conteúdo, à produção de um } \\
\text { julgamento de valor baseado em princípios éticos, morais, democráticos do } \\
\text { próprio indivíduo. }\end{array}$ \\
\hline $\begin{array}{c}\text { Criar para comunicar } \\
\text { (COMPETÊNCIAS) }\end{array}$ & $\begin{array}{l}\text { Diz respeito à capacidade de criar, editar e comunicar mensagens } \\
\text { mediáticas, usando várias técnicas e tecnologias mediáticas em vários } \\
\text { contextos. Em pormenor, refere-se ao uso da linguagem e ao uso de } \\
\text { técnicas de comunicação para produzir e disseminar conteúdos na esfera } \\
\text { pública. }\end{array}$ \\
\hline
\end{tabular}

Fonte: Adaptação de "Process skills: success for life" - Literacy for the 21st Century/Center for Media Literacy (2003: 28) (disponível em http://www.medialit.org/sites/default/files/mlk/ 01_MLKorientation.pdf)

9 Como salienta a psicologia cognitiva, "compreender" implica uma descodificação a partir de um manancial de conhecimento prévio (esquemas) que o sujeito mobiliza no processo. 


\section{Dimensões de análise: Técnica, crítica, criativa}

0 conjunto de domínios considerados pelo Media literacy expert group ("aceder", "compreender", "avaliar", "criar") como domínios sistémicos e interpenetrantes traduz a multidimensionalidade do próprio conceito de literacia mediática e pode inscrever-se em três macro-dimensões de análise: a dimensão técnica ${ }^{10}$, a dimensão crítica e a dimensão criativa. Estas dimensões correspondem, na sua essência, àquelas identificadas no modelo da literacia mediática dos 3 C's (Cultural, Critical e Creative) de que falam, por exemplo, Burn ou Reia-Baptista (Euromeduc, 2009); aos critérios identificados no modelo de literacia mediática da EAVI: Technical, Cognitive, Communicative (EAVI, 2009, 2011); ou no modelo de Helsper e Eynon (2013): Technical, Critical, [Social] e Creative.

As dimensões remetem de forma evidente para dois contextos ${ }^{11}$ (complementares) de análise: consumo e produção. 0 centro gravitacional dos "indivíduos mediáticos" é o consumo, a nova "antropologia" da sociedade contemporânea (Pérez-Tornero, 2007a, p. 201), conjunto de processos de apropriação, sistema de produção de sentidos (Martín-Barbero, 1997). 0 consumo está ligado a um tipo de experiência que podemos designar como "privada", no sentido de ser íntima e não coletiva, e em oposição à experiência "pública" ou "partilhada", aqui associada à produção mediática. A comunicação mediada é sempre um fenómeno social contextualizado: é implantada em contextos sociais que se estruturam de diversas formas e que produzem impacto na comunicação que ocorre (Thompson, 2009, p. 20).

Nestes termos, os contextos de "consumo" e "produção" estão assim, de forma mais ou menos evidente, relacionados com os dois tipos de operações de processamento da informação, já identificados. Adota-se o conceito de "consumo"

10 No nosso modelo corresponde a "Aceder".

11 Os grandes estudos extensivos de literacia consideram o "contexto", visto, por um lado, que a leitura se desenvolve em determinado ambiente social e, por outro, que a motivação para ler e a interpretação de mensagens podem ser influenciadas por ele. O PISA adotou a operacionalização das variáveis de "situação" do Common European Framework of Reference(CEFR), desenvolvido pelo Conselho da Europa, em 1996. Estas categorias foram adaptadas enquanto "contextos", a saber: 'pessoal', 'público', 'ocupacional' e 'educacional'. Fixemo-nos nos contextos 'pessoal' e 'público'. 0 contexto 'pessoal' relaciona-se com textos cuja intenção é satisfazer interesses pessoais, tanto práticos/utilitários como intelectuais. Nesta categoria, também se incluem os materiais cuja intenção é manter ou desenvolver relações pessoais com outros, como cartas ou emails. 0 contexto 'público' reporta à leitura de textos relacionados com atividades/assuntos sociais. Os textos associados a esta categoria incluem sítios web informativos e notícias impressas ou online, por exemplo. Nos mais recentes estudos internacionais de referência, como o PIAAC, por exemplo, as categorias de "contexto" foram identificadas como 'profissionais/ocupacionais'; ' 'pessoais' (onde se incluem as subcategorias 'casa e família'; ' 'saúde e segurança'; 'economia de consumo'; 'lazer e recreio'); 'comunitárias e de cidadania'; e 'educacionais e formativas'. No modelo EAVI (2009), a terminologia adotada faz a distinção entre 'competências pessoais' e 'competências sociais' (contexto 'individual'), o que nos parece pouco adequado aos objetivos. 
enquanto "receção"12 e enquanto operação de "descodificação"13; e 0 de "produção" enquanto operação de "codificação" no seu sentido clássico: a codificação de mensagens (a codificação de signos) num código (re)conhecido e partilhado por emissor e recetor, conceito transversal aos modelos do processo de comunicação ao longo da História ${ }^{14}$.

Tendo por base este espartilho teórico, construiu-se um primeiro modelo de análise:

Figura n. ${ }^{0} 3$ - Modelo de análise

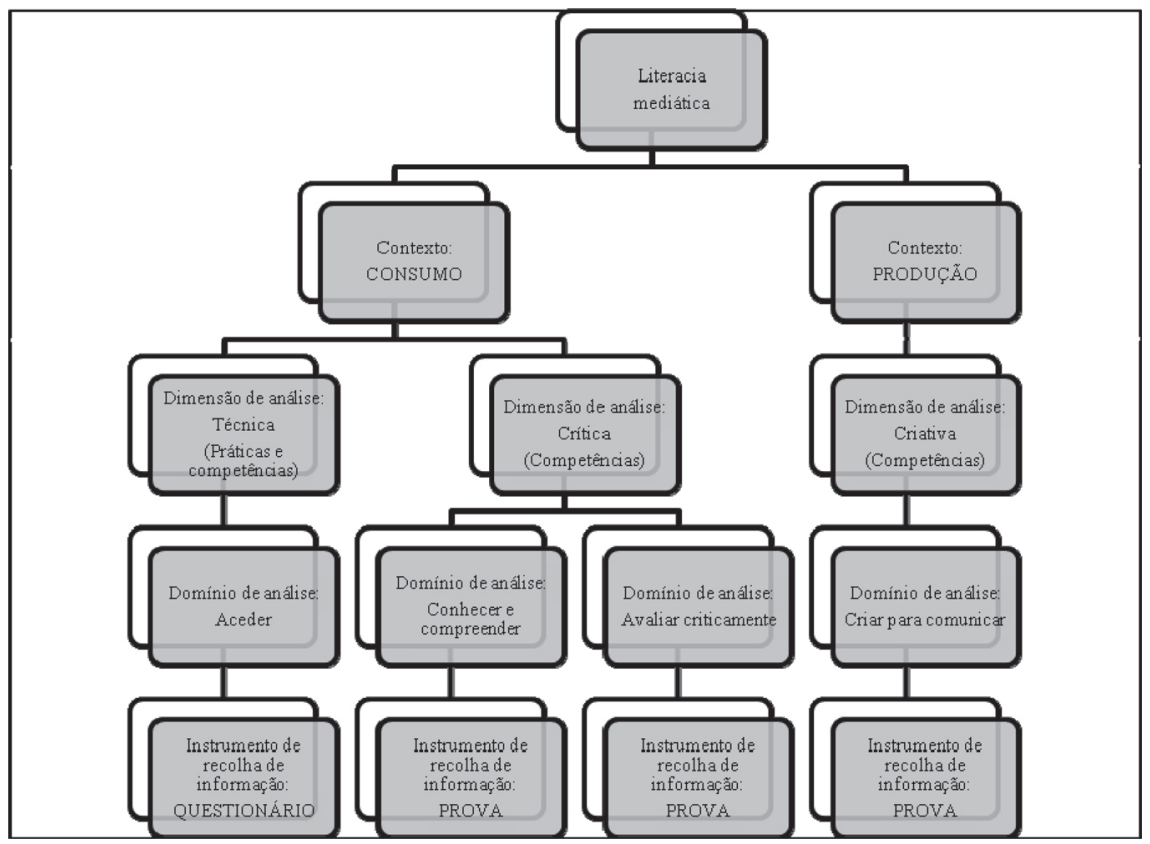

A literacia mediática é um recurso que os indivíduos mobilizam, uma espécie de "caixa negra" que possibilita não só o acesso e uso instrumental dos media (dimensão técnica), mas sobretudo a interpretação e avaliação crítica das culturas do quotidiano (Ferin, 2002), como a cultura multimediática (dimensão crítica). Aos cidadãos do século XXI pede-se que consumam informação mas também que a produzam, e de forma responsável e consciente (dimensão criativa). Pede-se que analisem criticamente mas também que criem reflexivamente. Pede-se que acedam ao conhecimento mas também que o partilhem com outros cidadãos, que intervenham no espaço público. Nas sociedades multimediáticas contemporâneas, exigem-se

12 Receção como "apropriação quotidiana", como em Thompson (1995) ou Silverstone (2005).

13 Descodificação em sentido lato, como em Ang (1985), Morley (1992), Silverstone et al. (1996) ou Fiske (1987).

14 Desde Aristóteles, que, com Arte Retórica, lança os fundamentos do processo de comunicação com "quem fala - que discurso faz - quem ouve", passando por Lasswell (1948), Shannon e Weaver (1949), Schramm (1960), Jakobson (1960) ou Hall (1980), por exemplo. 
cidadãos proativos, críticos, participativos. Como é já evidente, a PLM avalia competências circunscritas a duas (das três) dimensões: crítica e criativa. A cada uma destas dimensões (e respetivos domínios de análise) corresponde um conjunto de "operações de processamento".

Figura n. ${ }^{0} 4$ - Dimensões, domínios e operações de processamento

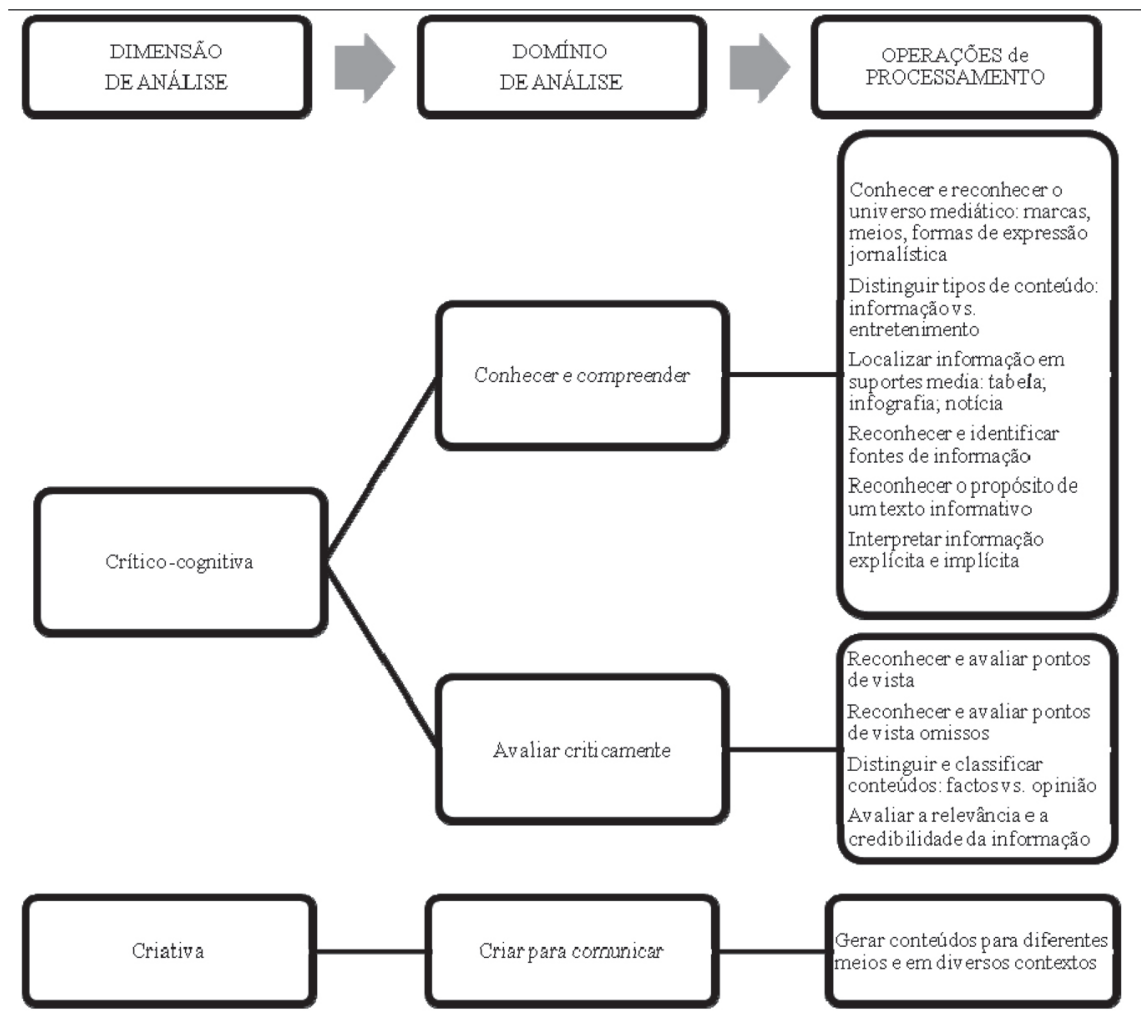

A identificação e construção destas operações de processamento resultaram da combinação reflexiva de várias fontes de informação: os programas de avaliação de competências de literacia ENL, PISA, IALS, ALL e PIAAC; os estudos europeus de literacia mediática Study on Assessment Criteria for Media Literacy Levels - Media Literacy Framework ${ }^{15}$ (EAVI, 2009) e Testing e Refining Criteria to Access Media Literacy Levels in Europe. Final Report' (2011) da EAVl; o conjunto de documentos produzidos pelo grupo de investigadores Euromeduc, reunidos em Media Literacy in Europe: Controversies, Challenges and Perspectives ${ }^{17}$ (2009); assim como 0 contri-

15 Disponível em http://ec.europa.eu/culture/media/literacy/docs/studies/eavi_annex_b_framework_rev_en.pdf en.pdf

16 Disponível em http://ec.europa.eu/culture/media/literacy/docs/final-report-ML-study2011_

17 Disponível em http://www.euromeduc.eu/IMG/pdf/Euromeduc_ENG.pdf 
buto de investigadores como van Dijk (1983a, 1983b, 1990, 2002, 2008, 2009), Quin e McMahon (1991, 1995), Potter (2001, 2004), Hobbs e Frost (2003), Arke (2005), Mihailidis (2008), Arke e Primack (2009) e Mathieu (2009).

\section{Os suportes}

Os suportes usados nesta pesquisa são materiais provenientes de fontes impressas ou digitais, apresentados aos inquiridos em formato papel. Para a avaliação da literacia mediática foi construída uma prova (a PLM), na qual são apresentados diversos conteúdos, a propósito dos quais são colocadas questões. Os conteúdos apresentados são rigorosamente, e na sua maioria, géneros jornalísticos, ou seja, formas narrativas de apresentação da informação nos media, modelos narrativos (ou rotinas) próprios do jornalismo e constituem as plataformas para a resolução das tarefas ou atividades.

Os consumos mediáticos estão a mudar. Nas últimas décadas, as TIC transformaram decisivamente a forma como aprendemos, nos informamos, comunicamos, enfim, a forma como vivemos em sociedade. Sendo assim, não faria qualquer sentido passar ao lado do mundo mediático digital, ainda que assumindo à partida, e de forma muito clara, a impossibilidade de avaliar de forma direta competências de literacia digital dos cidadãos com um teste em suporte pape ${ }^{18}$. Assim, a avaliação de competências de literacia digital é feita apenas de forma indireta, pela inclusão na PLM de suportes provenientes de websites informativos e de tarefas diretamente relacionadas com o meio.

Recuperando o modelo de Kirsch, Jungeblut e Mosenthal (1998), aplicado no IALS e no ALL, por exemplo, existem dois tipos de variáveis de interpretação do processo de informação escrita: as variáveis de legibilidade ou variáveis de estrutura, e as variáveis de processo.

Os suportes de informação escrita são as variáveis de legibilidade ou estrutura. Observemos, em pormenor, estas variáveis. Kirsch, Jungeblut e Mosenthal classificam os textos em contínuo e não-contínuo. 0 texto contínuo é o texto em prosa convencional: um conjunto de palavras que formam frases que formam parágrafos. São exemplos de textos contínuos os artigos de jornais e revistas, os manuais, as brochuras ou os emails. No texto não-contínuo, a informação encontra-se frequentemente organizada segundo uma lógica gráfica ou tipográfica, permitindo ao leitor diferentes estratégias de apropriação da informação: é o caso das tabelas, dos gráficos, das infografias ou dos formulários. Kirsch, Jungeblut e Mosenthal batizam 0 texto não-contínuo como 'documento'. Esta classificação de Kirsch e Mosenthal foi adotada nos grandes estudos internacionais de literacia, como o PISA, o IALS ou o ALL. Em alguns deles, como muito recentemente o PIAAC, a classificação é mais abrangente, incluindo o "texto misto" e o "texto múltiplo".

Na PLM, à classificação de Kirsch, Jungeblut e Mosenthal acrescentámos um outro tipo de variável na interpretação do processamento de informação: a imagem ${ }^{19}$. A imagem é aqui concebida como uma unidade de sentido (um "texto visual"), opção

18 Existiu, como é evidente, a impossibilidade (financeira e logística) de usar computadores portáteis no âmbito desta investigação.

19 Refira-se que a utilização de imagens é recorrente nas provas de numeracia do PIAAC. 
que tem por espartilho referencial teórico contributos de Peirce, Saussure, Barthes, Eco, Deleuze ou Moles, por exemplo. Indiscutivelmente, a sociedade contemporânea é uma sociedade da imagem - a civilização da imagem (ou a civilização do cliché, segundo Deleuze) -, da valorização da imagem, da massificação da imagem. Os media suportam e mantêm o "império" da imagem. 0 jornalismo é hoje, em larga medida, muito mais do que um produto linguístico: é também um produto visual não-linguístico (concordando com a classificação proposta, em 1976, por Eliseo Verón), isto é, gráfico, fotográfico, infográfico, iconográfico (Peltzer, 1992).

A classificação de suportes obriga ainda a uma maior especificação conceptual (cf. PISA, IALS, ALL, PIAAC). Para além do formato (texto contínuo, texto não-contínuo e imagem), os textos/imagens foram classificados segundo o meio de origem, isto é, a fonte (impressa ou digital) e o tipo de informação. A classificação dos suportes segundo o tipo de informação - ou modo narrativo, uma opção diretamente relacionada com a intencionalidade da mensagem - impôs a conceção de uma grelha de análise original. Foram criadas seis categorias:

- textual informativo, onde se incluem textos jornalísticos informativos (facts) de diferentes géneros, como a notícia e a reportagem;

- textual opinativo, onde se incluem textos jornalísticos opinativos (comments). como o artigo de opinião;

- textual prescritivo, onde se incluem textos de instrução ou doutrina, como o Código Deontológico do Jornalista;

- visual informativo, onde se incluem imagens com forte conteúdo informativo (facts) de diferentes géneros, como tabelas, infografias ou primeiras-páginas;

- visual opinativo, onde se incluem imagens com forte conteúdo opinativo (comments), como o cartoon;

- visual instrumental, onde se incluem imagens estereotipadas que ordenam (e reforçam) a cultura mediática, como o logotipo.

A seleção de cada um dos suportes prende-se, como é evidente, com a construção das tarefas sujeitas a medição, tendo em conta distintos graus de dificuldade. Essa seleção é orientada por três preocupações fundamentais:

- representação de uma vasta gama de suportes, assegurando uma diversidade linguística e iconográfica/visual tão ampla e rica quanto possível (diferentes géneros jornalísticos presentes nos media tradicionais e nos novos media);

- representação de uma vasta gama de suportes, passíveis de enquadramento em diferentes graus de complexidade;

- representação de uma vasta gama de suportes, traduzíveis num número suficiente de tarefas e enquadráveis em cada um dos domínios operacionais.

A cada um dos suportes corresponde um determinado número de tarefas, isto é, de atividades a desenvolver. 


\section{As tarefas}

A partir da identificação das grandes dimensões de análise (crítica, criativa), dos domínios operacionais (conhecer e compreender, avaliar criticamente, criar para comunicar), das operações de processamento e dos suportes, procedeu-se à conceção de tarefas.

As tarefas são tidas pelos investigadores como o ponto crucia/na avaliação direta de competências de literacia (Ávila, 2008, p. 137). São em rigor problemas, isto é, atividades específicas e diferenciadas que implicam a leitura e a interpretação de conteúdos e mensagens mediáticas presentes nos suportes e cuja resolução está relacionada com um (ou mais) suporte. A realização de cada uma das tarefas implica, em cada momento e de forma diversificada, a capacidade de mobilização de competências.

Segundo o modelo de Kirsch, Jungeblut e Mosenthal, as tarefas constituem 0 segundo tipo de variável: são as variáveis de processo ${ }^{20}$. Neste caso, há a considerar o tipo de associação, cuja medição resulta da relação entre o enunciado (onde é solicitada determinada operação, a resolução de determinado problema, geralmente sob a forma de uma pergunta) e o suporte (que apresenta um maior ou menor nível de densidade e complexidade). Kirsch identifica quatro tipos de operações com diferentes graus de dificuldade: localizar, relacionar, integrar e gerar.

$\mathrm{Na}$ PLM, numa primeira fase, optámos pela integração teórica deste modelo com o modelo PIAAC. À terminologia usada no PIAAC (cf. OECD, 2009) - 'localizar e identificar', 'integrar e interpretar' e 'avaliar e refletir' - juntámos a tarefa 'gerar' de Kirsch, Jungeblut e Mosenthal, possibilitando também a avaliação direta de competências criativas e comunicativas (contexto: produção; dimensão: criativa). Numa segunda fase, adaptámos a descrição de tarefas adotada no ENL (Benavente et al., 1996) e no PIAAC (OECD, 2009) a uma prova de literacia mediática. Em pormenor:

- localizar e identificar: Tarefas de nível 1. Implicam, por exemplo, a localização de informação, o reconhecimento e identificação de conteúdos e dos seus elementos distintivos (segmentos) em vários suportes. São as tarefas menos exigentes, tarefas básicas de interação como um texto ou um documento (em geral, um suporte pequeno e simples) que alavancam as tarefas dos níveis subsequentes.

- integrar e interpretar: Tarefas de nível 2. Implicam, por exemplo, a determinação (e associação) das principais ideias de um texto, a classificação de mensagens e de conteúdos mediáticos, a interpretação de informação explícita ou implícita, a relação/conexão entre diferentes partes de um texto. Requerem um processamento de informação mais elaborado.

20 Kirsch e Mosenthal consideram três variáveis de processo. Para além do tipo de associação, identificam o tipo de informação solicitada e a plausibilidade dos distractores. 0 tipo de informação solicitada refere-se à informação a encontrar no suporte, segundo as instruções presentes no enunciado. Informação mais concreta determina tarefas mais simples, informações mais abstratas determinam tarefas mais exigentes. A plausibilidade dos distractores diz respeito à existência de distractores nos suportes: informação semelhante à solicitada no enunciado mas que não the corresponde exatamente e, portanto, distrai. 
- avaliar e refletir: Tarefas de nível 3. Implicam, por exemplo, a avaliação de conteúdos, a seleção, organização e integração de informação proveniente de várias fontes, a capacidade de efetuar inferências sobre o texto ou a capacidade de relacionar ideias e de entender o texto como um todo, e de fundamentar uma ideia ou conclusão. Requerem um processamento de informação com um grau mais elevado de complexidade. Remetem para conhecimentos, ideias e valores do indivíduo, externos ao texto. Mais exigentes e mais abstratas.

- gerar: Tarefas do nível 4. As mais exigentes de todo o teste de literacia mediática. Implicam, por exemplo, a seleção, organização e processamento de informação em suportes complexos, mobilizando conhecimentos próprios especializados, a capacidade de organizar e editar uma mensagem segundo a lógica própria do jornalismo e tendo em vista a sua publicação em diferentes media e em diversos contextos.

A PLM encontra-se, portanto, organizada em torno de quatro tipos de tarefa que, por sua vez, se encontram organizadas em níveis (1 - 4). Esta organização em níveis não é original: por exemplo, W. James Potter teorizou, em 2004, uma organização em níveis de literacia mediática e José Manuel Pérez-Tornero e Tapio Varis (2010) retomaram, alguns anos mais tarde, essa metodologia operatória.

Este tipo de estrutura motivou novo desenho do modelo:

Figura n. ${ }^{0} 5$ - Dimensões, domínios e tarefas
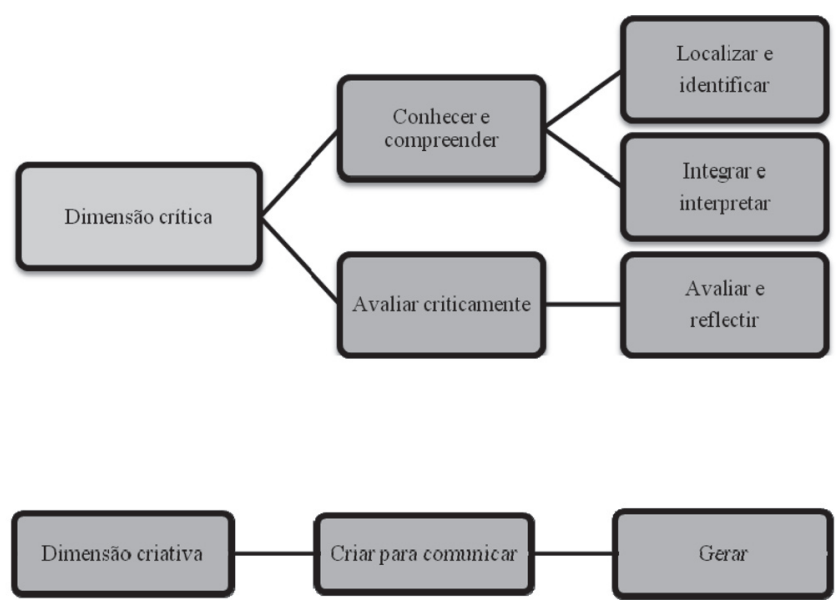


\section{A avaliação de competências}

Um breve sumário do framework da PLM revela um modelo operacional estruturado em dimensões (crítica, criativa), domínios (conhecer e compreender, avaliar criticamente, criar para comunicar) e respetivas operações de processamento, com caracterização de variáveis de estrutura (suportes) e de variáveis de processo (tarefas).

A avaliação direta de competências de literacia (nomeadamente mediática) exige a definição do grau de dificuldade de cada uma das tarefas e esse grau de dificuldade resulta "da inter-relação entre o que é suscetível de se designar, abreviadamente, por dificuldade teórica e por dificuldade empírica" (Benavente et al., 1996, p. 66). Esta metodologia, concebida e testada com êxito no Estudo Nacional de Literacia - ENL (1996, coordenação de Ana Benavente), revela-se adequada aos objetivos.

Assim, a definição do grau de dificuldade das tarefas acontece, a um nível teórico, graças ao cruzamento entre variáveis de estrutura (formato, meio, tipo) e variáveis de processo (tipo de associação), isto é, o modelo teórico "conceptualiza a dificuldade das tarefas em função da complexidade dos suportes (em termos de estrutura, extensão e forma gráfica) e do grau de complexidade das operações de processamento da informação necessárias à resolução das tarefas (do reconhecimento literal, localização direta e cálculo numérico simples a inferências complexas, geração de sínteses e resolução de problemas implicando operações encadeadas)" (Benavente et al., 1996, pp. 65-66).

Este modelo teórico surge no momento de construção da prova (concretamente, na fase de escolha dos suportes e na fase de formulação de tarefas) e no momento de análise de resultados, confrontando o grau de dificuldade das tarefas previsto teoricamente com o grau de dificuldade verificado empiricamente (Benavente et al., 1996, p. 66).

Deste processo reflexivo resulta uma matriz de enquadramento das tarefas por grau de dificuldade, a partir do cruzamento entre variáveis de estrutura e variáveis de processo. À partida, foram considerados quatro níveis de dificuldade em cada um dos eixos (o eixo vertical da matriz diz respeito à complexidade das variáveis de processo, ou seja, das operações; 0 eixo horizontal da matriz diz respeito à complexidade das variáveis de estrutura, ou seja, dos suportes). As tarefas mais difíceis são, em rigor, as que resultam do cruzamento entre operações mais complexas (níveis 3 e 4) vs. suportes mais complexos (níveis 3 e 4).

A um nível empírico, a definição do grau de dificuldade das tarefas pode ter por base a percentagem de respostas certas a cada uma das operações (quanto menos respostas certas, maior a dificuldade da tarefa). A avaliação de cada uma das tarefas resulta de um processo de valoração: a cada tarefa será atribuído um valor (1 ou 0 , consoante a resposta esteja certa ou errada, 9 no caso de não resposta - missing; em alguns casos, 2, 1 ou 0, consoante a resposta esteja certa, parcialmente certa ou errada, 9 no caso de não resposta - missing).

Nas próximas páginas, apresentam-se alguns exemplos de tarefas, dos quatro níveis de dificuldade, presentes na PLM. 
Exemplo de tarefas de nível 1:

Dimensão: Crítica

Domínio: Conhecer e compreender

Tarefa: Localizar e identificar

Figura n. ${ }^{\circ} 6$ - Exemplo de tarefas de nível 1

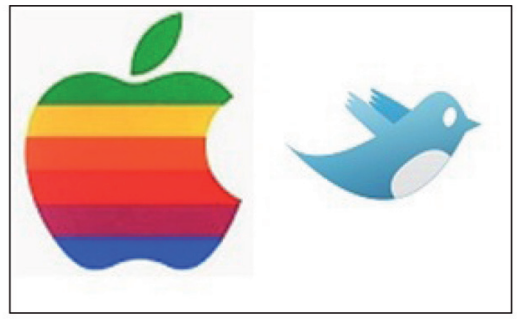

Identifique os logótipos:

Quadro n. ${ }^{0} 2$ - Guião de avaliação da questão "Identifique os seguintes logótipos"

\begin{tabular}{|l|l|}
\hline Pergunta: & Identifique o seguinte logótipo \\
\hline Formato do suporte: & Imagem \\
\hline Tipo de suporte: & Visual instrumental: Logótipo \\
\hline Meio de origem: & Digital \\
\hline Tarefa: & Localizar/ldentificar \\
\hline Objetivo: & Reconhecer e identificar um signo do universo mediático: marca \\
\hline
\end{tabular}

\begin{tabular}{|l|l|}
\hline Pergunta: & Identifique o seguinte logótipo \\
\hline Formato do suporte: & Imagem \\
\hline Tipo de suporte: & Visual instrumental: Logótipo \\
\hline Meio de origem: & Digital \\
\hline Tarefa: & Localizar/Identificar \\
\hline Objetivo: & Reconhecer e identificar um signo do universo mediático: marca \\
\hline
\end{tabular}


Exemplo de uma tarefa de nível 2:

\title{
Dimensão: Crítica \\ Domínio: Conhecer e compreender \\ Tarefa: Integrar e interpretar
}

\author{
Figura n. ${ }^{0} 7$ - Exemplo de uma tarefa de nível 2
}

\begin{abstract}
Código Deontológico do Jorna lista
1. O jornalista deve relatar os factos com rigor e exactidâo e interpretá-los com honestidade. Osfactos devem ser comprovados, ouvindo as partes com interesses atendiveis no caso. A distinção entre notícia e opiniäa deve ficar bem clara aos olhos do público.

2. O jornalista deve combater a censura e o sensacionalismo e considerar a acusação sem provas e o plágio como graves faltas profissionais.

3. 0 jornalista deve lutar contra as restriçōes no acesso àsfontes de informação e as tentativas de limitar a liberdade de expressão e o direito de informar. É obrigação do jornal ista divulgar as of ensasa estes direitos.

4. O jornalista deve utilizar meios legais para obter informações, imagens ou documentos e proibir-se de abusar da boa-fé de quem quer que seja. A identificaçãa como jrnalista é a regra e outros processos só podem justificar-se por razões de incontestável interesse público.

5. O jornalista deve assumir a responsabilidade por todos os seus trabalhos e actos prof issionais, assim como promover a pronta rectificação das informaçōes que se revelem inexactas ou falsas. $O$ jornalista deve também recusar actos que violentem a sua consciência.

6. O jornalista deve usar como critério fundamental a idertificação das fontes. O jornalista não deve revelar, mesmo em juizo, as suas fontes confidenciais de informação, nem desrespeitar os compromissos assumidos, excepto se o tentarem usar para canalizar informações falsas. As opiniões devem ser sempre atribuidas.

7. O jornalista deve salvaguardar a presunçăo de inocência dos arguidos até a sentença transitar em julgado. 0 jomalista não deve identificar, directa ou indirectamente, as vítimas de crimes sexuais e os delinquentes menores de idade, assim como deve proibir-se de humilhar as pessoas ou perturbar a sua dor.

8. O jornalista deve rejeitar o tratamento discriminatório das pessoas em função da cor, raça, credos, nacionalidade, ou sexo.

9. O jornalista deve respeitar a privacidade dos cidadăos excepto quando estiver em causa o interesse público ou a conduta do individuo contradiga, manif estamente, valores e princípios que publicamente defende. 0 jomalista obriga-se, antes de recolher declarações e imag ens, a atender às condições de serenidade, liberdade e responsabilidade das pessoas envolvidas.

10. O jornalista deve recusar funções, tarefas e benefícios susceptiveis de comprometer o seu estatuto de independência e a sua integridade profissional. O jornalista não deve valer-se da sua condição profíssional para noticiar assuntos em que tenha interesse.

A provado em 4 de Maio de 1993
\end{abstract}


Após a leitura do Código Deontológico do Jornalista, diga se é verdadeira $(\mathbf{V})$ ou falsa $(\mathbf{F})$ a deguinte afirmação:

\title{
0 jornalista deve trabalhar, simultaneamente, como relações públicas
}

\author{
Quadro n. ${ }^{0} 3$ - Guião de avaliação da questão "0 jornalista deve trabalhar, \\ simultaneamente, como relações públicas"
}

\begin{tabular}{|l|l|}
\hline Pergunta: & $\begin{array}{l}\text { Após a leitura do 'Código Deontológico do Jornalista' diga se é verda- } \\
\text { deira (V) } \\
\text { ou falsa (F) a seguinte afirmação: } \\
\text { O jornalista deve trabalhar, simultaneamente, como relações pú- } \\
\text { blicas }\end{array}$ \\
\hline Formato do suporte: & Contínuo \\
\hline Tipo de suporte: & Textual prescritivo: Código deontológico profissional \\
\hline Meio de origem: & Impresso \\
\hline Tarefa: & Integrar/Interpretar \\
\hline Objetivo: & Interpretar informação implícita e inferir por dedução \\
\hline
\end{tabular}

Exemplo de tarefas de nível 3:

\section{Dimensão: Crítica \\ Domínio: Avaliar criticamente \\ Tarefa: Avaliar e refletir}

Figura n. ${ }^{0} 8$ - Exemplos de tarefas de nível 3

\section{É proibido conquistar}

4 de Julho de 2011 por Vitor Rainho (SOL)

Ponto prévo. tenho pelos voladores o mesmo apreço que tenho por um assassino. Isto é nojo e repulsa e gosto de os ver na cadera.

Vem esta conversa a propósito das folclóricas manifestacóes intituladas Slutwalks ou Marcha das Galdérias. Vamos a historia. Un policia canadiano tontaço foi a uma universidade de Toronto defender a ideia peregrina de que a mehor forma de as mulheres evitarem ser violadas era deixarem de se vestir como unas galderias.

A história passou se em Janeiro e, desde entâo, a comocăo tomou conta de raparigas indefesas que se manifestaram em mais de 70 cidades por esse mundo. Vestidas para matar, de freiras ou de bimbas. muitas empunhavam cartazes a dizer que têm todo o direito de se apresentarem como galdérias sem que isso dé o direito a quem quer que seja de as importunar. Não posso estar mais de acordo, embora tenham que ter cuidado con a zona que frequentam.

Mas voltemos ás nossas galdérias actuais. Dizem tambem nos cartazes que podem vestir-se como quiserem, mas não estão para ser importunadas, leia-se não querem ouvi um piropo ou uma tentativa de seducăo. Mas o mundo está louco? Como é que seria o mundo sem seduçáo? Carregava-se num botão na internet e aparecia o desejo? Que as pessoas nâo importunem as outras, parece-me claro como a água. Agora que náo possam mostrar agrado, roça a tonteria. 


\section{Galdérias portuguesas vão sair à rua em protesto}

\section{2 de Junho de 2011 por Paula Cosme Pinto (EXPRESSO.PT)}

Decotes, mini-saias, collarts de rede, calcas bem justas ao rabo, saltos altos (como náo podia deixar de ser), vestidos provocantes. no próximo sábado, as muheres portuguesas vão dar largas a imaginaçáo (e ao guarda-roupa) para sairem a rua na primeira "Slut Walk" (qualquer coisa como "Narcha das Galdérias") em Portugal.

Comecaram em abril e confesso que terho vindo a assistir com alquma curiosidade as proporcóes que estas "SlutWalks" contra o machismo ten ganho. A ideia partiu de um grupo de mulheres canadianas, após as declaraçóes de um policia que dizia: "as mulheres devern evilar vestir-se de forma provocante se não quiserem ser voladas". A ndignação do mundo dos saltos altos espalhou-se como um rastiho e a "Marcha das Galdérias" chegou a mais de 70 cidades, desde Sidney, a Londres e Brasilia. Será um sinal de que comentáros tåo idiotas como o deste senhor polícia săo, afinal, comuns nos mais diversos paises? Parece que sim.

Ontem li o manifesto da marcha portuguesa e fez-me sentido. Já escrevi aqui váras vezes esta frase e hoje volto a dizé lo nada justifica uma volação. E se é preciso imos para a rua descascadas, en protesto para consegurem perceber isto, então que seja. Faço minhas as palavas do manifesto.

Após a leitura dos textos de Vítor Rainho e Paula Cosme Pinto, responda às perguntas: Qual a principal ideia que cada autor expressa no seu texto? Na sua opinião, há referências que possam ser consideradas discriminatórias? Justifique as suas respostas com alguns exemplos.

Quadro n. ${ }^{0} 4$ - Guião de avaliação da questão “Qual a principal ideia que cada autor expressa no seu texto? Na sua opinião, há referências que possam ser consideradas discriminatórias?"

\begin{tabular}{|l|l|}
\hline Pergunta: & $\begin{array}{l}\text { Após a leitura dos textos de Vítor Rainho e Paula Cosme Pinto, res- } \\
\text { ponda às perguntas: Oual a principal ideia que cada autor expressa } \\
\text { no seu texto? Na sua opinião, há referências que possam ser consi- } \\
\text { deradas discriminatórias? Justifique as suas respostas com alguns } \\
\text { exemplos. Vítor Rainho }\end{array}$ \\
\hline Formato do suporte: & Contínuo \\
\hline Tipo de suporte: & Textual opinativo: Opinião \\
\hline Meio de origem: & Digital \\
\hline Tarefa: & Avaliar/Refletir \\
\hline Objetivo: & Reconhecer e avaliar o ponto de vista do autor (o argumento) \\
\hline
\end{tabular}

\begin{tabular}{|l|l|}
\hline Pergunta: & $\begin{array}{l}\text { Após a leitura dos textos de Vítor Rainho e Paula Cosme Pinto, res- } \\
\text { ponda às perguntas: Qual a principal ideia que cada autor expressa } \\
\text { no seu texto? Na sua opinião, há referências que possam ser consi- } \\
\text { deradas discriminatórias? Justifique as suas respostas com alguns } \\
\text { exemplos. Paula Cosme Pinto }\end{array}$ \\
\hline Formato do suporte: & Contínuo \\
\hline Tipo de suporte: & Textual opinativo: Opinião \\
\hline Meio de origem: & Digital \\
\hline Tarefa: & Avaliar/Refletir \\
\hline Objetivo: & Reconhecer e avaliar o ponto de vista do autor (o argumento) \\
\hline
\end{tabular}


Exemplo de uma tarefa de nível 4:

\section{Dimensão: Criativa \\ Domínio: Criar para comunicar \\ Tarefa: Gerar/Criar}

Figura n. ${ }^{\circ} 9$ - Exemplo de uma tarefa de nível 4

\begin{tabular}{|c|c|c|c|c|c|}
\hline \multicolumn{6}{|c|}{ Quadro 1. Literacia de leitura, matemática e ciểncias de alunos com idade entre os 15-16 anos (2009) } \\
\hline Leitura & Média & Matemática & Média & Ciências & Médilia \\
\hline Coreia do Sul & 539 & Coreia do Sul & 546 & Finlândia & 554 \\
\hline Finlândia & 536 & Finlândia & 541 & Japäo & 539 \\
\hline Canadá & 524 & Suíça & 534 & Coreia do Sul & 538 \\
\hline Nova Zelândia & 521 & 」ара̃o & 529 & Nova Zelândia & $53: 2$ \\
\hline Japão & 520 & Canadá & 527 & Canadá & 529 \\
\hline Austrália & 515 & Holanda & 526 & Estónia & 528 \\
\hline Holanda & 508 & Nova Zeländia & 519 & Austrälia & 527 \\
\hline Bélggica & 506 & Bélgica & 515 & Holanda & 522 \\
\hline Noruega & 503 & Austrália & 514 & Alemanha & 520 \\
\hline Estónia & 501 & Alemanha & 513 & Suiça & 517 \\
\hline Suliça & 501 & Estónia & 512 & R. Unido & 514 \\
\hline Polónia & 500 & Islândia & 507 & Eslovénia & 512 \\
\hline Islândlia & 500 & Dinamarca & 503 & Polónia & 508 \\
\hline Estados Unidos & 500 & Eslovénia & 501 & Irlanda & 508 \\
\hline Suécia & 497 & Noruega & 498 & Bélgica & 507 \\
\hline Alemanha & 497 & França & 497 & Hungria & 503 \\
\hline Irlanda & 496 & Eslovăquia & 497 & Estados Unidos & 502 \\
\hline França & 496 & Áustria & 496 & R. Checa & 500 \\
\hline Dinamarca & 495 & Polónia & 495 & Noruega & 500 \\
\hline R. Unido & 494 & Suécia & 494 & Dinamarca & 499 \\
\hline Hungria & 494 & R. Checa & 493 & França & 498 \\
\hline Portugal & 489 & R. Unido & 492 & Islândia & 496 \\
\hline Itália & 486 & Hungria & 490 & Suécia & 495 \\
\hline Letónia & 484 & Luxemburgo & 489 & Áustria & 494 \\
\hline Eslavénia & 483 & Estados Unitos & 487 & Letónia & 494 \\
\hline Grécia & 483 & Irlanda & 487 & Portugal & 493 \\
\hline Espanha & 481 & Portugal & 487 & Lituânia & 491 \\
\hline R. Checa & 478 & Espanha & 483 & Eslováquia & 490 \\
\hline Eslováquia & 477 & Itália & 483 & Itália & 489 \\
\hline Israel & 474 & Letónia & 482 & Espanha & 488 \\
\hline Luxemburgo & 472 & Lituânia & 477 & Luxemburgo & 484 \\
\hline Áustria & 470 & Grécia & 466 & Grécia & 470 \\
\hline Lituânia & 468 & Israel & 447 & Israel & 455 \\
\hline Turquia & 464 & Turquia & 445 & Turquia & 454 \\
\hline Chile & 449 & Bulgária & 428 & Chile & 447 \\
\hline Bulgária & 429 & Roménia & 427 & Bulgária & 439 \\
\hline México & 425 & Chile & 421 & Roménia & 428 \\
\hline Roménia & 424 & México & 419 & México & 416 \\
\hline $\begin{array}{r}\text { Fonte: PISA } 2009 . \\
\text { Do pon } \\
\text { Do pon } \\
\text { Do pon }\end{array}$ & $\begin{array}{l}\text { tistico, sig } \\
\text { tistico, se } \\
\text { tístico, sig }\end{array}$ & $\begin{array}{l}\text { Ca tiva mente acima } \\
\text { hante à media da } \\
\text { cativamente abaix }\end{array}$ & da $O C D$ & & ALO \\
\hline
\end{tabular}

0 Quadro 1 (em cima) revela os rankings do programa de avaliação de competências PISA 2009 (leitura, matemática e ciências). Escreva uma notícia, para ser publicada num jornal português, diário e de referência (por exemplo, o jornal 'Público'). Use o esquema básico de construção do lead da notícia (o que aconteceu, a quem, onde, quando, como e porquê). 
Quadro n. ${ }^{0} 5$ - Guião de avaliação da questão “Escreva uma notícia, para ser

publicada num jornal português, diário e de referência (por exemplo,

o jornal 'Público'). Use o esquema básico de construção

do lead da notícia (o que aconteceu, a quem, onde, quando,

como e porquê)"

\begin{tabular}{|l|l|}
\hline Pergunta: & $\begin{array}{l}\text { O Quadro 1 (em cima) revela os rankings do programa de avaliação } \\
\text { de competências PISA 2009 (leitura, matemática e ciências). Escreva } \\
\text { uma notícia, para ser publicada num jornal português, diário e de re- } \\
\text { ferência (por exemplo, o jornal "Público"). Use o esquema básico de } \\
\text { construção do lead da notícia (o que aconteceu, a quem, onde, quan- } \\
\text { do, como e porquê). }\end{array}$ \\
\hline Formato do suporte: & Não-contínuo \\
\hline Tipo de suporte: & Visual informativo: Infografia \\
\hline Meio de origem: & Impresso \\
\hline Tarefa: & Gerar \\
\hline Objetivo: & $\begin{array}{l}\text { Selecionar, organizar e gerar informação, tendo em conta a natureza } \\
\text { do meio (imprensa) }\end{array}$ \\
\hline
\end{tabular}

\section{Notas finais}

Quando falamos em literacia mediática, falamos em práticas e em competências. Esta distinção conceptual, de base, motivou a conceção de um instrumento de recolha de informação muito específico - a PLM -, cujo processo reflexivo de operacionalização aqui foi detalhadamente revelado. 0 principal contributo deste documento para a área científica das ciências sociais, e em particular para o domínio da literacia mediática, é, manifestamente, teórico-metodológico.

A multidimensionalidade da literacia mediática evidenciou limitações quanto à opção metodológica tomada e quanto à abrangência da prova de literacia mediática nas sociedades atuais: (multi)mediáticas, (multi)tecnológicas, em rede.

A opção metodológica adotada (metodologia quantitativa-extensiva) desvendou muito sobre "o quê" e muito pouco sobre o "porquê". Em investigações futuras, recomenda-se uma pluriabordagem metodológica, com recurso a metodologias quantitativas-extensivas e qualitativas-intensivas.

Por fim, o facto de a prova se materializar num caderno de exercícios impresso em papel constitui uma limitação evidente, a nível da avaliação de competências de literacia mediática digital, nomeadamente as competências relacionadas com 0 acesso a/uso de plataformas tecnológicas/tecnologia para a resolução de problemas e para a execução de tarefas mais ou menos complexas, e da integração de novos problemas e de novas operações adequadas a cenários tecnológicos digitais. Neste sentido, o framework conceptual da prova de literacia mediática deverá ser, em futuras investigações, objeto de atualização, tendo em conta diferentes plataformas, novos formatos e mais tarefas. Uma revisão e adequação da prova à captação de uma diversidade de práticas e competências de literacia mediática no "mundo digital" - integrando tarefas de rotina, mas também tarefas que requerem competências especializadas e complexas, nomeadamente no domínio da comu- 
nicação - servirá diferentes objetivos e possibilitará a avaliação de práticas e de competências relacionadas com a Web 2.0, no que respeita à navegação (e às ferramentas de navegação), à interatividade e à participação online, à criação, organização e partilha de conteúdos (em hipertexto) em rede, nas redes.

\section{Referências}

Ang, I. (1985). Watching Dallas: Soap Opera and the Melodramatic Imagination. Londres: Methuen \& Co.

Arke, E. (2005). Media literacy and critical thinking: Is there a connection?. Tese de Doutoramento, Duquesne University, Pittsburgh, Pennsylvania, Estados Unidos da América.

Arke, E. T. \& Primack, B. A. (2009). Quantifying media literacy: Development, reliability and validity of a new measure. Educational Media International, 46(1), 53-65.

Aufderheide, P. \& Firestone, C. M. (1993). Media Literacy: A Report of the National Leadership Conference on Media Literacy. Queenstown: Aspen Institute.

Ávila, P. (2008). A Literacia dos Adultos - Competências-chave na Sociedade do Conhecimento. Oeiras: Celta.

Ávila, P., Costa, A. F., Ramos, P., Botelho, M. C., Mauritti, R. \& Rodrigues, E. (2011). Programa Internacional para a Avaliação das Competências dos Adultos (PIAAC): Relatório de Atividades 2010, Lisboa: CIES-ISCTE.

Barthes, R. (1989). Elementos de Semiologia. Lisboa: Edições 70.

Benavente, A., Rosa, A., Costa, A. F. \& Ávila, P. (1996). A Literacia em Portugal: Resultados de Uma Pesquisa Extensiva e Monográfica. Lisboa: Fundação Calouste Gulbenkian.

Burn, A. (2009). Process and outcomes. What to evaluate and how? In Euromeduc (Ed.), Media Literacy in Europe: Controversies, Challenges and Perspectives, 61-69. Bruxelas: Euromeduc.

Coleman, J. S., Anthony, S. \& Morrison, D. E. (2009). Public Trust in the News. A Construction Study of the Social Life of the News. Oxford: Reuters Institute for the Study of Journalism - University of Oxford.

Comunicação da Comissão ao Parlamento Europeu, ao Conselho, ao Comité Económico e Social Europeu e ao Comité das Regiões: Uma Abordagem Europeia da Literacia Mediática no Ambiente Digital (COM 2007. 833).

Costa, A. F. (2003). Competências para a sociedade educativa: Questões teóricas e resultados de investigação. In Almeida, J. F. (Ed.), Cruzamentos de Saberes. Aprendizagens Sustentáveis (179-194). Lisboa: Fundação Calouste Gulbenkian.

Deacon, D., Fenton, N. \& Bryman, A. (1999). From inception to reception: The natural history of a news item. Media, Culture and Society, 21(1), 5-31.

Deleuze, G. (1990). A Imagem-Tempo. São Paulo: Editora Brasiliense.

Directiva 2007/65/CE do Parlamento Europeu e do Conselho de 11 de Dezembro de 2007 que altera a Directiva 89/552/CEE do Conselho relativa à coordenação de certas disposições legislativas, regulamentares e administrativas dos Estados-Membros relativas ao exercício de actividades de radiodifusão televisiva. 
Eco, U. (1987). A Estrutura Ausente. São Paulo: Editora Perspectiva.

Euromeduc (2009). Media Literacy in Europe: Controversies, Challenges and Perspectives. Bruxelas: Euromeduc.

European Association for Viewers Interests - EAVI (coord.) (2009). Study on Assessment Criteria for Media Literacy Levels. Final Report. Bruxelas: Comissão Europeia.

European Association for Viewers Interests - EAVI (coord.) (2011). Media Literacy: Testing and Refining Criteria to Access Media Literacy Levels in Europe. Final Report. Bruxelas: Comissão Europeia.

Fairclough, N. (1995). Media Discourse. Londres: Edward Arnold.

Fedorov, A. (2003). Media education and media literacy: Expert's opinion, UNESCO - MENTOR: A Media Education Curriculum for Teachers in the Mediterranean. The Thesis of Thessaloniki.

Ferin, I. (2002). Comunicação e Culturas do Quotidiano. Lisboa: Quimera.

Feuerstein, M. (1999). Media literacy in support of critical thinking. Journal of Educational Media, 24(1), 43-55.

Fiske, J. (1987). Television Culture, Londres: Routledge

Fowler, R. (1991). Language in the News: Discourse and Ideology in the Press. Londres: Routledge.

Gagné, E. D., Yekovich, C. W. \& Yekovich, F. R. (1993). The Cognitive Psychology of School Learning. Nova lorque: Harper Collins.

Goffman, E. (1974). Frame Analysis. An Essay on the Organization of Experience. Boston: Northeastern University Press.

Hall, S. (1980). Encoding, decoding in the television discourse. In Hall, S., Hobson, D., Lowe, A. \& Willis, P. (Eds.), Culture, Media, Language (128-138), Londres: Hutchinson.

Hall, S., Critcher, C., Jefferson, T., Clarke, J. \& Roberts, B. (1990). The social production of news. In Marris, P. \& Thornham, S. (Eds.), Media Studies. A Reader (645-652). Edimburgo: Edinburgh University Press.

Hall, S, Critcher, C., Jefferson, T., Clarke, J. \& Roberts, B. (1999). A produção social das notícias: 0 mugging nos media. In Traquina, N. (Org.), Jornalismo. Questões, Teorias e "Estórias" (224-248). Lisboa: Veja.

Helsper, E. \& Eynon, R. (2013). Pathways to digital literacy and engagement. European Journal of Communication, 28(6), 696-713.

Hobbs, R. (1998). The seven great debates in the Media Literacy Movement, Journal of Communication, 48(1), 16-32.

Hobbs, R. \& Frost, R. (2003). Measuring the acquisition of media literacy skills. Reading Research Quarterly, 38, 330-352.

Jakobson, R. (1960). Closing statement: Linguistics and poetics. In Sebeok, T. (Ed.), Style in Language (350-377). Cambridge: MIT Press.

Jenkins, H., Purushotma, R., Weigel, M., Clinton, K. \& Robison, A. J. (2007). Confronting the Challenges of Participatory Culture: Media Education for the 21 ${ }^{\text {st }}$ Century. Massachussetts: MacArthur Foundation/MIT Press. 
Jensen, K. B. (1991). When is meaning? Communication theory, pragmatism and mass Media reception. In Anderson, J. A. (Ed.), Communication Yearbook - 14 (3-32). Newbury Park (CA): Sage.

João, S. G. \& Menezes, I. (2008). Construção e validação de indicadores de literacia mediática. Comunicação e Sociedade, 13, 55-68.

Katz, E., Gurevitch, M. \& Haas, H. (1973). On the use of the mass media for important things. American Sociological Review, 38(2), 164-181.

Kirsch, I. (2001). The International Adult Literacy Survey (IALS): Understanding What Was Measured. Princeton: ETS - Educational Testing Service.

Kirsch, I., Jungeblut, A., Jenkins, L. \& Kolstad, A. (1993). Adult Literacy in America: A First Look at the Results of the National Adult Literacy Survey. Washington: National Center for Education Statistics.

Kirsch, I., Jungeblut, A. \& Mosenthal, P. (1998). The measurement of adult literacy. In Adult Literacy in Murray, T. S., Kirsch, I. \& Jenkins, L. (Orgs.). OECD Countries: Technical Report on the First International Adult Literacy Survey. Washington, US Department of Education - National Center for Education Statistics.

Kist, W. (2005). New Literacies in Action: Teaching and Learning in Multiple Media. Nova Iorque: Teachers College Press.

Lahire, B. (1992). Discours sur l'illetrisme et cultures écrites. Remarques sociologiques sur en problème social. In Besse, J-M. Gaulmyn, M-M., Ginet, D. \& Lahire, B. (Eds.), L'Illetrisme en Question (59-75). Lyon: Press Universitaires de Lyon.

Lasswell, H. (1948). The structure and function of communication in society. In Bryson, L. (Ed.), The Communication of Ideas (37-51). Nova lorque: Institute for Religious and Social Studies.

Levy, F. (2010). How technology changes demands for human skills. OECD Education Working Paper 45.

Livingstone, S. (2003). The changing nature and uses of media literacy. Media@lse Electronic Working Paper, 4.

Livingstone, S. (2004a). Media literacy and the challenge of new information and communication technologies. Communication Review, 7(1), 3-14.

Livingstone, S. (2004b). What is media literacy?. Intermedia, 32(3), 18-20.

Livingstone, S. (2011). Media Literacy: Ambitions, Policies and Measures, Media@|se.

Martín-Barbero, J. (1997). Dos Meios às Mediações: Comunicação, Cultura e Hegemonia. Rio de Janeiro: Editora UFRJ.

Masterman, L. (1985). Teaching the Media. Londres: Routledge.

Mathieu, D. (2009). Cultural knowledge in news comprehension. Journal of Audience \& Reception Studies, 6(1), 77-117.

McQuail, D. \& Windahl, S. (2003). Modelos de Comunicação para o Estudo da Comunicação de Massas. Lisboa: Editorial Notícias.

Mead, G. H. (1926). The nature of aesthetic experience. International Journal of Ethics, 36, 382-392.

Mihailidis, P. (2008). Beyond cynicism. How media literacy can make students more engaged citizens. Tese de Doutoramento, University of Maryland, Estados Unidos da América. 
Moles, A. (1969). Teoria da Informação e Percepção Estética. Rio de Janeiro: Tempo Brasileiro. Morais, J. (1997). A Arte de Ler. Psicologia Cognitiva da Leitura. Lisboa: Edições Cosmos. Morais, J. (2002). Influência da literacia e da escolaridade sobre a linguagem e a cognição. In Viana, F. L., Martins, M. \& Coquet, E. (Eds.), Leitura, Literatura Infantil e Ilustração (45-62). Investigação e Prática Docente - 3. Braga: Centro de Estudos da Criança da Universidade do Minho.

Morais, J. (2010). How learning to read changes the cortical networks for vision and language. Science, 330: 1359-1364.

Morley, D. (1992). Television, Audience and Cultural Studies. Londres: Routledge.

OECD (2009). PIAAC Literacy: A Conceptual Framework. Paris: OECD.

Peirce, C. S. (1977). Semiótica. São Paulo: Editora Perspectiva.

Peltzer, G. (1992). Jornalismo Iconográfico. Lisboa: Planeta Editora.

Pereira, L. (2013). Literacia Digital e Políticas Tecnológicas para a Educação. Santo Tirso: De Facto Editores.

Pérez-Tornero, J. M. (Coord.) (2007a). Comunicação e Educação na Sociedade da Informação. Novas Linguagens e Consciência Cívica. Porto: Porto Editora.

Pérez-Tornero, J. M. (Coord.) (2007b). Study on the Current Trends and Approaches to Media Literacy in Europe. Bruxelas: Comissão Europeia.

Pérez-Tornero, J. M. \& Varis, T. (2010). Media Literacy and New Humanism. Moscovo: UNESCO.

Potter, W. J. (2001). Media Literacy. Thousand Oaks: Sage.

Potter, W. J. (2004). Theory of Media Literacy: A Cognitive Approach. Thousand Oaks: Sage.

Quin, R. \& McMahon, B. (1991). Media analysis: Performance in media in western Australian government schools. Western Australian Ministry of Education Report.

Quin, R. \& McMahon, B. (1995). Evaluating standards in media education. Canadian Journal of Educational Communication, 22(1), 15-25.

Reia-Baptista, V. (2009). Media literacy and Media Appropriations by Youth. In Euromeduc (Ed.), Media Literacy in Europe: Controversies, Challenges and Perspectives (181-165). Bruxelas: Euromeduc.

Rumelhart, D. E. (1977). Toward an interactive model of reading. In Dornic, d. S. (Ed.), Attention and Performance 6 (573-503). Hillsdale (NJ): Erlbaum.

Rychen, D. S. \& Salganik, L. H. (Orgs.) (2003). Key Competencies for a Successful Life and a Well-Functioning Society. Gottingen: Hogrefe \& Huber Publishers.

Saussure, F. (1978). Curso de Linguística Geral. Lisboa: Dom Quixote.

Schramm, W. (Ed.) (1960). Mass Communications, Urbana: Univ. of Illinois Press

Shannon, C. E. \& Weaver, W. (1949). The Mathematical Theory of Communication. Urbana: University of Illinois Press.

Silverblatt, A. (2001). Media Literacy: Keys to Interpreting Media Messages. Westport: Praeger Publishers.

Silverstone, R. (2005). Mídia e vida cotidiana: Elementos para uma teoria da mediação. Revista Brasileira de Ciências da Comunicação, 28(2), 127-137. 
Silverstone, R., Hirsch, E. \& Morley, D. (1996). Tecnologias de la información y de la comunicación y la economía moral de la familia. In Silverstone, R. \& Hirsch, E. (Eds.), Los Efectos de la Nueva Comunicación (39-58). Barcelona: Bosch.

Sorlin, P. (1997). Mass Media. Oeiras: Celta.

Thoman, E. (2003). Skills and Strategies for Media Education. Santa Monica: Center for Media Literacy (CML).

Thoman, E. \& Jolls, T. (2003). Literacy for the 21 ${ }^{\text {st }}$ Century - An Overview \& Orientation Guide to Media Literacy Education. Santa Monica: Center for Media Literacy (CML).

Thompson, J. B. (1995). Ideologia e Cultura Moderna. Petrópolis: Vozes.

Thompson, J. B. (2009). A Mídia e a Modernidade. Uma Teoria Social da Mídia. Petrópolis: Editora Vozes.

Tuchman, G. (1978). Making News: A Study in the Construction of Reality. Nova lorque: Free Press.

Van Dijk, T. A. (1983a). Estructuras textuales de las noticias de prensa. Análisis. Quaderns de Comunicació i Cultura, 7/8, 77-105.

Van Dijk, T. A. (1983b). Discourse analysis: Its development and application to the structure of news. Journal of Communication, 33(3), 20-43.

Van Dijk, T. A. (1988). News Analysis. Case Studies of International and National News in the Press. Hillsdale: Lawrence Erlbaum Associates Publishers.

Van Dijk, T. A. (1990). La Noticia como Discurso. Comprensión, Estrutura e Producción de la Información. Barcelona: Paidós.

Van Dijk, T. A. (2002). El conocimiento y las noticias. Quaderns de Filologia. Estudis de Comunicació, 1, 249-270.

Van Dijk, T. A. (2008). Discourse and Context: A Sociocognitive Approach. Cambridge: Cambridge University Press.

Van Dijk, T. A. (2009). Society and Discourse: How Social Contexts Influence Text and Talk. Cambridge: Cambridge University Press.

Verón, E. (1975). A Produção de Sentido. São Paulo: Cultrix.

Verón, E. (1976). Lenguaje y Comunicación Social. Buenos Aires: Nueva Visión.

Whitehurst, G. J. \& Lonigan, C. J. (2001). Emergent literacy: Development from prereaders to readers. In Neuman, S. B. \& Dickinson, D. K. (Eds.), Handbook of Early Literacy Research (11-29). Nova lorque: Guilford Press. 